\title{
Mudanças na distribuição da renda nacional em período de transformação
}

\author{
TADEUSZ KOWALIK
}

A PROBLEMÁTICA DE DISTRIBUiÇÃo da renda nacional e de igualdade ou desigualdade com ela relacionadas constituem questões das mais controvertidas. As posições dos economistas estão tão distantes entre si que a obtenção de consenso se torna quase impossível, até mesmo dentro de uma idéia liberal bastante abrangente. Mencionarei aqui as concepções mais importantes, ou melhor, grupos (escolas) de concepções.

- O adversário mais conseqüente de qualquer ingerência do Estado na esfera da distribuição da renda nacional e de qualquer tentativa de igualar rendas através do Estado é Hayek (1967). Ele se opõe categoricamente à própria idéia de justiça social e considera que igualar rendas constitui algo contrário à idéia de liberdade e ao princípio fundamental da igualdade perante a lei; uma violação dessa lei resultaria, pois, na introdução de direitos desiguais aos cidadãos. $\mathrm{O}$ autor considera como recurso extremo até mesmo o auxílio governamental aos inválidos e doentes os quais, em princípio, deveriam ser assistidos por grupos pequenos e naturais (família, vizinhos, igreja). O objetivo da política econômica numa sociedade livre "nunca poderá ser o de assegurar vantagens específicas para determinado grupo de pessoas" (Hayek, 1967:377). Segundo o autor, o Estado não pode realizar tal tarefa adequadamente por operar com agregados e o seu apoio com freqüência não chegaria onde fosse realmente necessário. A redistribuição da renda deforma burocraticamente a alocação racional de recursos. Apesar de Hayek ainda ter adeptos para a sua teoria, neste aspecto não conseguiu maior apoio, nem mesmo entre os entusiastas de suas outras concepções.

- Talvez o grupo mais numeroso seja aquele de economistas que percebem a redistribuição de renda como uma despesa, fator que diminui a rentabilidade econômica. Tal grupo entretanto é claramente heterogêneo em questões de política do Estado. Dois são os seus subgrupos mais importantes:

o primeiro considera que a redistribuição da renda representa efetivamente uma despesa. Em nome da justiça social, porém, não se deve concordar com uma distribuição de renda exclusivamente através do mecanismo de mercado. O mais conhecido teórico dessa tendência é Artur 
Okun, que foi um dos principais conselheiros da equipe de J.F. Kennedy. O próprio título de sua principal obra já expõe esse dilema: Equality and efficiency: the big trade-off (1975). Mais especificamente, o dilema de Okun (1983:607) seria o seguinte: "Em geral, sendo a igualdade de rendas ao mesmo tempo desejada e custosa, a solução 'ótima' envolverá um compromisso: um sacrifício da eficiência a fim de obter mais igualdade do que a que existiria na ausência de ação social, mas tolerância de mais desigualdade do que a que seria preferida, na ausência de custos" (Okun, 1983: 607);

o segundo, bastante numeroso, critica sistematicamente a crescente participação do Estado no PIB, considerando-a um processo de ocaso do capitalismo. Tal corrente de pensamento foi iniciada por Schumpeter que já em 1918 tratou o crescimento do "país de impostos" como a expressão do afastamento das regras do jogo capitalista. Ao desenvolver as idéias de Schumpeter e de Hayek, Simpson (1994) analisa seriamente até que ponto é atual o sinistro prognóstico dos dois pensadores sobre a transformação do capitalismo em socialismo. Por sua vez Burton (1984), outro economista, nega claramente a denominação de capitalismo para as atuais economias ocidentais. Diversos autores lembram que Reagan e Thatcher chegaram ao poder prometendo aos eleitores reduções na receita e na despesa nacionais, promessas que não conseguiram realizar. Nos anos 1979-1992, todos os países do Grupo dos 7 aumentaram a participação dos gastos no PIB (os alemães obtiveram sucesso inicialmente, o qual foi, porém, anulado pelo custo da anexação da República Democrática Alemã - RDA).

- O dilema de Okun foi há tempos questionado por vários defensores do modelo escandinavo [ver, entre outras, publicações de Walter Korpi]. Ultimamente enfrenta oposição mesmo nos Estados Unidos. Os discípulos de Okun na Brookings Institution, em Washington, abalam sua tese principal, argumentando que pesquisas empíricas não confirmam a sua hipótese. Baseados em experiências da economia norte-americana (Baily et al, 1993), demandam uma política consciente contra as desigualdades que vêm crescendo nos últimos dois decênios, argumentando que elas não contribuíram para o aumento da eficiência da referida economia. Por outro lado, alguns economistas mostram que países mais igualitários alcançaram maior progresso econômico - ou pelo menos não menor - que os países com maior diferenciação de renda (Freeman, 1991). O Banco Mundial publicou recentemente interessante pesquisa, referente principalmente a países asiáticos recém-industrializados, demonstrando que "pequenas reduções de desigualdades estimulam o crescimento econômico" (Birdsdall et al, 1995) (1).

Coloca-se em dúvida a conhecida tese de que o aumento do salário mínimo leva ao aumento do desemprego. As últimas pesquisas realizadas indicam que o aumento significativo dos salários mínimos entre 1990 e 1991 influenciou 
minimamente (se é que influenciou) a redução de empregos (Mishel et al, 1995) (2). Milward (1995), historiador da economia européia, está convencido que a origem do boom de pós-guerra está no considerável engajamento do Estado na economia: na construção de moradias econômicas, na corajosa elevação das rendas do trabalho e na ampliação do welfare state (3). Com relação aos países póscomunistas, são os autores do livro [relatório] Transformation and Integration que formulam de maneira mais precisa o postulado de maior igualdade como um dos fatores de eficiência. Afirmam eles: "para muitos, o postulado de igualdade tem um caráter político, é um objetivo desejado por si próprio. Nós vamos bem mais longe: achamos que maior igualdade constitui uma das condições de maior eficiência. Enquanto as possibilidades potenciais dos indivíduos não servirem para o aumento do bem-estar, seja para eles mesmos, seja para a sociedade, a eficiência continuará baixa” (Eatwell et al, 1995:7).

\section{"Revolução" na estrutura de rendas}

À luz da grande divergência de opiniões a respeito da distribuição de renda, torna-se ainda mais difícil entender a razão dessa problemática ser uma das mais negligenciadas ou mesmo ignoradas pelos economistas na literatura sobre as transformações sistêmicas. Atkinson \& Micklewright (1992), pesquisadores ocidentais sobre problemas de distribuição de renda na Europa Central e Oriental, com razão acusam os economistas de desinteresse por tais problemas (4). Mencionam extensa lista de exemplos desse tipo de desinteresse (5), entre outros, o das instituições financeiras internacionais engajadas em processos de transformação. Em um dos relatórios do FMI, por exemplo, pode-se ler: "Devemos contar com o fato de que, em época de transformação, haverá crescimento de desigualdades; entretanto, importante para a política é a preocupação com o padrão de vida mínimo para os pobres e não a questão da desigualdade em geral" (Atkinson \& Micklewright, 1992:3). A base dessa proposição, provavelmente, seria a suposição de que os mecanismos de mercado levam a desigualdades que na economia de mercado seriam necessárias para seu funcionamento normal. Entretanto, considerando-se uma eleição, não são apenas os pobres que votam. Os mais miseráveis sequer exercem esse direito. E a maioria dos eleitores julga a economia, o sistema econômico, a política econômica e mesmo os políticos, principalmente em termos de renda, isto é, em termos do que os indivíduos e os vários grupos ganham, em comparação com o que ganhavam anteriormente e com o que eles próprios ganham atualmente. Tal aspecto é importante, principalmente em período de queda da renda nacional e, portanto, de queda absoluta das rendas de parte considerável da sociedade. O instinto de conservação deveria, portanto, levar os políticos a terem maior sensibilidade com relação à problemática da distribuição de renda.

Mesmo com a manutenção das mesmas regras e princípios, a distribuição de renda modifica-se em virtude, por exemplo, de mudanças demográficas como envelhecimento da população, alterações em seu nível de saúde, elevação dos níveis educacionais (6). Nos Estados Unidos, muitos autores enfatizam atual- 
mente a elevação no nível de instrução como o caminho mais seguro em direção à redução das desigualdades, ou ao menos de redução do processo de seu aprofundamento, que é observado no país há mais de dois decênios. Todavia, existe aí um círculo vicioso. Rendas baixas, e principalmente a sua queda, não favorecem a melhoria do ensino.

As mudanças mencionadas manifestam-se, contudo, ao longo de maior período de tempo. Para a elaboração do presente trabalho interessaram-nos principalmente as mudanças radicais que tiveram lugar na Polônia nos últimos seis ou sete anos. A origem dessas mudanças foram principalmente as reformas e as pouco controladas modificações do sistema, principalmente a violenta expansão do setor privado. Deixaremos de lado aqui a questão da distribuição da renda nacional entre consumo e investimento por constituir outro assunto, embora tal divisão gere também importantes conseqüências para a renda da população. Lembremos apenas que, no curto prazo, o baixo nível de investimentos constituiu um amortizador para a queda no nível do consumo, mais fraca que a queda no nível da produção. Concomitantemente, porém, o baixo nível de investimentos tornou-se uma das principais causas do desemprego em massa e da sua transformação em desemprego permanente.

A passagem da economia do socialismo real para a economia de mercado necessariamente resultou em nova estrutura de rendas da sociedade. $\mathrm{O}$ professor Bywalec (1995:9) define as modificações na distribuição da renda nacional que tiveram lugar nos anos 1989-1990 como revolucionárias, e isto tanto no que se refere à sua profundidade, quanto - e principalmente - à sua rapidez. Na tabela 1 , a seguir, apresenta um quadro dessas mudanças.

Tabela 1

Polônia: dinâmica da renda pessoal real da população nos anos 1989-1993

\begin{tabular}{|c|c|c|c|c|c|}
\hline Ano & 1990 & 1991 & 1992 & 1993 & $1993 / 1989$ \\
\hline Remunerações & 67,7 & 97,3 & 87,9 & 95,0 & 55,0 \\
\hline $\begin{array}{l}\text { Benefícios } \\
\text { sociais pecuniários }\end{array}$ & 85,7 & 139,8 & 99,0 & 102,0 & 112,3 \\
\hline $\begin{array}{l}\text { Rendas do trabalho } \\
\text { de agricultores }\end{array}$ & & & & & \\
\hline individuais & 50,1 & 81,3 & 113,8 & 111,0 & 51,4 \\
\hline $\begin{array}{l}\text { Rendas da atividade } \\
\text { econômica (exceto }\end{array}$ & & & & & \\
\hline agricultura) ** & 147,5 & 97,2 & 142,1 & 120,0 & 244,3 \\
\hline Total das rendas * & 85,3 & 105,9 & 103,5 & 105,0 & 98,2 \\
\hline
\end{tabular}

* Para as primeiras quatro colunas, ano anterior $=100 . \bullet *$ Abrangem as rendas de atividade econômica das pessoas físicas sócias de empresas e fundações, assim como de trabalhadores autônomos; descontadas as despesas com investimentos relativas à produção e descontados os ganhos financeiros.

Fonte: Bywalec (1995:9), com base em Anuário Estatístico 1993 e 1994; em cálculos e estimativas de Bywalec relativos ao ano de 1993 . 
A participação de grupos específicos da população na sua renda total (estrutura de renda) modificou-se conforme indicado na tabela 2 .

Tabela 2

Polônia: estrutura das rendas da população 1989 e 1993

\begin{tabular}{lcc}
\hline \multicolumn{1}{c}{ Rendas } & 1989 & 1993 \\
\hline Remunerações & 46,2 & 28,2 \\
Benefícios sociais & 15,7 & 20,1 \\
Rendas de agricultores individuais & 13,5 & 6,3 \\
Rendas da atividade & & \\
econômica (exceto agricultura) $^{*}$ & 7,2 & 17,5 \\
Total das rendas & 100,0 & 100,0 \\
\hline
\end{tabular}

* Abrangem as rendas da atividade econômica das pessoas físicas, sócios de empresas e fundações, assim como trabalhadores autônomos, descontadas as despesas com investimentos relativas à produção e descontados os ganhos financeiros.

Fonte: Bywalec (1995:9), com base em Anuário Estatístico 1993 e 1994; cálculos e estimativas de Bywalec relativos ao ano de 1993 .

As duas tabelas ilustram profundas mudanças na estrutura da renda dos principais grupos da população, talvez sem precedentes na história econômica da Polônia. As maiores modificações aconteceram no primeiro e - com relação aos agricultores - durante o segundo ano da implementação do Plano Balcerowicz. A grande queda das rendas individuais atingiu tanto agricultores quanto trabalhadores assalariados. As rendas dos agricultores caíram quase à metade em 1990, e ainda mais $20 \%$ no ano seguinte, como conseqüência da redução dos subsídios para produtos agrícolas e, principalmente, da importação de produtos alimentícios fortemente subsidiados no Ocidente, em um período de drástica queda do poder aquisitivo dos trabalhadores. Na verdade, tal fato ocorreu após um ano excepcionalmente favorável (1989) para os produtores rurais, quando os preços dos produtos agrícolas subiram radicalmente devido à sua liberação. Uma comparação com 1988 - ano considerado mais normal -, entretanto, pouco atenua essa queda. É evidente que, na estrutura da renda, os agricultores, representando quase $25 \%$ da força de trabalho nacional ativa, recebem por seu labor apenas $6,25 \%$ da renda da população do país, refletindo um rendimento significativamente menor do trabalho na agricultura quando comparado ao dos demais segmentos da economia. Além disso, os preços nacionais dos produtos agrícolas continuam sob influência da agricultura da Europa Ocidental, não somente mais produtiva, mas também fortemente subsidiada.

As estatísticas oficiais, assim como as pesquisas de orçamentos familiares tendem a diminuir tanto os ganhos provenientes do trabalho quanto os lucros. É de conhecimento geral que as empresas do setor privado, principalmente as menores (em número dominante também com relação às cifras de emprego), não revelam totalmente nem os seus lucros, nem as remunerações realmente pagas 
(visando à redução do pagamento de impostos, bem como das contribuições para fundos de seguro social). Como a participação do setor privado está crescendo rapidamente, tal aspecto pode influir na diminuição da dinâmica dos salários em geral. Varias pesquisas, entretanto, indicam que a queda dos salários reais está próxima de 33\% e se mantém em nível pouco abaixo: em 1994, os salários reais eram 28\% mais baixos que em 1989 (Beskid \& Deniszczuk, 1995). Não deixa de ser interessante, senão alarmante, o fato de que os dois primeiros anos de reaquecimento econômico provocaram uma queda adicional de salários.

A redução dos salários reais estava inscrita no programa de estabilização, do qual uma das "ancoras" era a constituição de significativa barreira (indicador de indexação e de impostos) contra a elevação de salários. Essa barreira por muito tempo não foi corrigida, apesar de as outras bases do programa terem se revelado distantes da realidade: o crescimento inicial dos preços foi muito mais elevado que o previsto, assim como foi menor a queda da inflação (ainda atualmente, após seis anos, o nível de inflação é superior ao estimado para o final de 1990); a redução do emprego e da produção foi muitas vezes mais elevada do que a prevista.

A queda drástica tanto das remunerações quanto das rendas do trabalho na agricultura levaram a um aumento correspondente dos gastos com subsídios, tanto na forma de auxílios aos desempregados quanto de benefícios sociais. Cresceu também de forma significativa o fundo de aposentadorias e pensões, já que a maior parte dos trabalhadores despedidos aproveitou as facilidades existentes para se aposentar mais cedo ou obter pensão por invalidez. Devido a tais atitudes, a participação do fundo de benefícios sociais na renda geral da população aumentou mais de $25 \%$. Cresceu também o número de pessoas cujas rendas provêm, total ou parcialmente, de recursos orçamentários. Juntamente com os empregados no setor estatal da economia, representam parcela significativa da sociedade. É conforme a definição de J. Sachs (Sachs, 1993), uma contradição interna do programa de rápida abertura da economia, do "salto para a economia do mercado". Seu objetivo declarado era a diminuição do papel do Estado, ou seja, a desestatização da economia e da sociedade. No entanto, as mudanças projetadas consistiram principalmente em transferir grande parte das pessoas do setor nacional da economia - portanto, vivendo do trabalho remunerado - para a esfera social. Criou-se assim um "estado social neoliberal", muito especifico e nãodesejado por ninguém (7).

Evidentemente, nem todos os trabalhadores assalariados e agricultores individuais pertencem à categoria dos derrotados. Um reduzido grupo de camponeses-agricultores, especializando-se habilmente em determinados setores de produção, aproveitou a oportunidade criada por maiores possibilidades de exportação. O número daqueles que obtiveram êxito entre o total de agricultores é, entretanto, muito pequeno e não influencia o resultado no quadro geral da drástica redução de seus rendimentos. Nas aldeias, o número de indivíduos ricos situados fora da estatística oficial é, certamente, inferior ao da cidade. Por outro lado, no grupo de trabalhadores assalariados houve sensível crescimento dos gru- 
pos extremos (de renda elevada e de renda baixa): de um lado, o trabalho nãoqualificado é muito mal remunerado e, de outro, é cada vez maior a remuneração recebida pelos trabalhadores altamente qualificados, principalmente no setor privado. Em geral, a classe com instrução superior, empregada no setor empresarial, teve ganhos. Houve mudanças também nos valores das remunerações nos diversos segmentos econômicos. O que se nota é principalmente a contínua queda dos salários dos trabalhadores do setor público nos segmentos educação, cultura e saúde. Em 1994, o salário real de trabalhadores do setor de educação caiu para aproximadamente $80 \%$, e o de trabalhadores dos serviços de saúde para $75,2 \%$ da média geral dos salários dos trabalhadores em empresas privadas (Departament, 1995). Mesmo na área governamental, apareceram novas diferenciações. Cresceram rapidamente os salários nas áreas de administração, segurança e finanças públicas; reduziram-se os dos professores e trabalhadores nos serviços de saúde (pública). Trata-se de uma situação com raízes no socialismo real, que se viu acentuada. É um paradoxo, tanto mais que a oposição democrática aproveitava, na sua luta contra o antigo regime, a conhecida frase de Lenin de que um salário mais alto para o policial que para o professor é característica de um Estado policial.

O traço mais característico das modificações que vêm ocorrendo na distribuição da renda nacional refere-se ao surgimento de dois nítidos pólos sociais: o grupo numeroso de pessoas vivendo abaixo do nível de pobreza e o pouco numeroso, de pessoas ricas ou em processo de rápido enriquecimento. Tal modificação é tanto mais frustrante por ter ocorrido em condições de queda geral do Produto Nacional Bruto (PNB) e das rendas individuais, quanto - o que também é importante - em condições de uma notável restrição do consumo coletivo em setores como serviços públicos de saúde, educação e cultura, com drástica redução dos subsídios oferecidos pelas empresas às suas equipes de trabalhadores. De acordo com pesquisas utilizando vários critérios para os limites de pobreza, o número de pobres é atualmente algumas vezes maior que no final dos anos 80 (Deniszczuk, 1995; Beskid \& Deniszczuk, 1995). O fator básico que cria ou aprofunda a pobreza é o desemprego em massa. $\mathrm{O}$ aparecimento de significativo grupo de indivíduos empregados, mas que vivem abaixo do nível de pobreza é fenômeno novo. Enquanto em 1989 apenas 3,8\% de empregados recebiam remuneração inferior à metade da média na economia nacional, em 1994 esse número elevou-se para $11 \%$. Aumentou também o contingente de empregados com salários inferiores à média nacional.

Pesquisas realizadas sobre o segundo pólo social infelizmente encontramse em estado embrionário. No entanto, varias observações parciais indicam "o aparecimento de um grupo pouco numeroso muito rico (alguns referem-se até a oligarquia financeira). A vitalidade das mudanças ocorre principalmente nos rendimentos mais elevados, em conseqüência de imprevisões legais e da falta de controle sobre os processos de abertura e privatização, bem como de suas patologias. Tal processo é acompanhado por consumo ostensivo, que constitui expressão da situação material e fonte de prestígio para indivíduos com altas rendas. 
Entre as pessoas realmente ricas, desapareceram rapidamente as características que compunham o status material, até então típico na Polônia. A falta de restrições aos rendimentos permitiu que todos os elementos das condições de existência (moradia, bens duráveis, recursos patrimoniais, entre outros) pudessem também se amoldar a um nível mais elevado" (Beskid \& Deniszuk, 1995). Às classes mais ricas pertencem não apenas os proprietários de grandes empresas, mas também os seus gerentes, cujos rendimentos anuais chegam, às vezes, a US\$ 100 mil.

As médias das rendas individuais no nível nacional escondem mudanças na sua distribuição em âmbito territorial. Nos últimos anos, o direcionamento da economia para o mercado e a sua abertura para o mundo, criaram oportunidades muito maiores para as províncias (voivodias) centrais, ocidentais e meridionais da Polônia, que para as setentrionais e orientais. A participação desigual na distribuição da renda nacional reflete, naturalmente, a participação desigual na sua criação. Nas regiões mais desenvolvidas o PIB per capita, em 1992, era duas vezes e meia maior do que nas regiões mais atrasadas (UNDP, 1995:203). De forma correspondente, embora não proporcional, são bem mais elevados os rendimentos oriundos de propriedades rurais das primeiras províncias com relação ás segundas. A tabela 3 ilustra a diferenciação espacial das rendas nas cinco províncias mais desenvolvidas e nas cinco menos desenvolvidas.

Tabela 3

Polônia: diferenciação espacial das rendas das propriedades rurais em 1992

$($ Polônia $=100)$

\begin{tabular}{lrlr}
\hline \multicolumn{2}{l}{ Províncias de maiores rendas } & \multicolumn{2}{l}{ Províncias de menores rendas } \\
\hline Varsóvia & 131,2 & Przemysl & 82,6 \\
Poznan & 121,3 & Tarnobrzeg & 81,6 \\
Cracóvia & 114,5 & Siedlce & 80,9 \\
Katowice & 114,0 & Ostroleka & 80,3 \\
Lodz & 112,8 & Suwalki & 79,5 \\
\hline
\end{tabular}

Fonte: UNDP, 1995:206.

Não se dispõe, na verdade, de dados diretamente comparáveis quanto ao periodo anterior à transformação. Contudo, tendo-se tornado o desemprego o fator principal de influência nas modificações no nível da renda nacional e no nível de vida, sua estatística poderá servir de medida aproximada das crescentes desigualdades regionais. Nas províncias mais pobres, geralmente rurais, o desemprego apresenta-se, como regra, várias vezes maior que nas províncias e grandes cidades industrializadas: enquanto, por exemplo, em 1994, nas províncias de Varsóvia, Cracóvia e Poznan o nível de desemprego oscilava entre 7,5\% e 8,8\%, nas de Slupsk, Suwalki e Olsztyn chegava a 30\%. "Existem regiões nas quais o número de desempregados ultrapassa o número de empregados. Quando do fechamento de uma grande fábrica ou de uma empresa agrícola estatal, muitos estabelecimentos locais ficaram sem a necessária infra-estrutura econômica. Fi- 
cou especialmente dramática a situação das regiões rurais periféricas pouco desenvolvidas, onde não existe a possibilidade de criação de novos locais de trabalho" (UNDP, 1995:207). Em linhas gerais, nos últimos anos aprofundou-se de forma intensa a diferenciação econômica entre a aldeia e a cidade, assim como entre a Polônia A e a Polônia B.

Evidentemente, torna-se necessário lembrar que as modificações ocorridas na distribuição da renda não refletem plenamente as modificações no nível de vida dos diferentes grupos populacionais. A estatística da distribuição de renda nacional constitui indicador falho do nível de vida dos diferentes grupos da população, e é considerado dos menos precisos. Não ficam demonstradas alterações na qualidade de vida pela eliminação das carências, além de a própria renda pecuniária ser apenas um - apesar de o mais importante - dos fatores que compõem o nível de vida da população. Nos últimos decênios, e especialmente nos últimos anos, muito se tem publicado a respeito da avaliação do desenvolvimento social (buman development), com a utilização de ampla gama de indicadores (UNDP, 1995).

\section{Mudanças controladas e imprevistas}

A necessidade de mudanças na distribuição de renda foi até certo ponto inscrita em todas as opções de distanciamento do socialismo real em favor da economia de mercado. Em uma concepção mais geral, quase todos os políticos e economistas aceitavam o aumento da desigualdade na distribuição da renda nacional: tanto os que queriam introduzir, no menor tempo possível, uma economia de mercado do tipo ocidental, quanto os que optavam por uma economia mista; e até aqueles cujas propostas de reforma do sistema anterior não iam, em princípio, além do seu enquadramento institucional. Parte das propostas de reformas restringia-se a aumentar a motivação no trabalho dos operários e dos gerentes, usando para tanto remunerações mais diferenciadas. A transformação polonesa, entretanto, foi acompanhada desde o início por discussões sobre o seu ritmo, sobre o sistema pretendido e sobre o modelo econômico de mercado mais adequado para as condições polonesas. Tais questões achavam-se intimamente ligadas com o problema da distribuição da renda nacional. Os partidários da primeira opção criaram um programa de estabilização e de transformações sistêmicas básicas e puseram-no em ação. A realização desse programa, na práti$\mathrm{ca}$, gerou resultados longe dos esperados. Apenas uma parte do processo foi conduzida pela política econômica. Tornou-se evidente, atualmente, para os adeptos das várias opções, que os custos sociais provaram ser bem mais elevados do que se supunha inicialmente e que o processo de formação do novo sistema vai demorar bem mais do que se esperava. A realidade, distante das intenções, levou a alguns de seus co-autores e executores à radical revisão dos conceitos iniciais do processo de mudança do sistema (8). A queda do PNB foi muito maior que a estimada, houve queda da produção industrial, dos salários reais e também dos rendimentos auferidos no campo; por outro lado, os preços elevaram-se muito mais do que se imaginava em conseqüência da chamada inflação corretiva. 
Por trás de todas essas mudanças ocorreram aquelas relativas à esfera social. A idéia de desestatização da economia e da sociedade obteve êxito apenas parcial. A radical redução da produção e do emprego no setor estatal, assim como a retirada do Estado do processo de alocação de recursos, geraram a necessidade de expansão do papel do Estado a fim de impedir patologias sociais. A introdução do sistema de mercado (ainda muito falho) tinha por objetivo constituir alternativa à redução do papel do Estado, o que - como já mencionado - não aconteceu. Também ficou provado que a escolha de "modelos ocidentais testados" não significou em absoluto o fim da experimentação. A edificação do capitalismo conforme projeto pré-determinado, mesmo que baseado em "modelos conferidos", sempre apresenta resultados distantes dos esperados.

A nova estrutura distributiva e as tendências de sua evolução posterior formaram-se tanto sob a influência das autoridades quanto esponta-neamente. Por sua vez, nas atuações das autoridades pode-se distinguir as que - pelo menos em princípio - correspondiam às suas aspirações, e aquelas que eram expressão de processos não-controlados. Pode-se afirmar que, após o primeiro período de realização do Plano Balcerowicz, a política sócio-econômica foi dirigida (e continua a sê-lo) segundo diretrizes do FMI já citadas, ou seja, interessando-se e tomando decisões quase que exclusivamente com relação às rendas mais baixas (realizando a sua correção periódica).

A política governamental foi a principal força fomentadora de mudanças radicais, tanto das desejadas quanto das não-pretendidas. A transferência de milhões de pessoas da esfera produtiva para a esfera social, a abertura da economia para a concorrência estrangeira - um verdadeiro Eldorado para o nascimento e desenvolvimento de empresas privadas - eram resultados pretendidos do Plano Balcerowicz.

O crescimento do setor privado foi abrupto, em escala talvez sem precedentes. Na Polônia, assim como na maioria de outros países pós-comunistas, em apenas alguns anos este setor tornou-se dominante; atualmente (primeiro semestre de 1996), emprega cerca de dois terços do total de trabalhadores e responde por mais da metade do PNB. A rápida expansão das empresas privadas fez com que, nas rendas individuais da população, crescesse a parcela devida à atividade econômica por conta própria. Na tabela 1 , já apresentada, são indicadas as rendas das empresas privadas, diminuídas das despesas de investimento. Entretanto, se for observado o crescimento da renda como expressão do aumento da riqueza ou do poder econômico desse grupo, todos os tipos de renda serão importantes.

A criação de uma classe média, que deveria constituir a base da democracia e do mercado, um apoio político ao poder público, foi também objetivo claramente manifestado pela política econômica. Apesar de os lucros da atividade econômica terem crescido de maneira radical, poucos são os indícios de ter sido assim constituída uma base para o governo ou para a democracia. Conseguiu-se reduzir o número de pessoas dependentes da renda do Estado, mas esse número foi ínfimo. 
A inflação elevada reduziu o valor real da renda individual em conta corrente, dos créditos, das habitações, dos automóveis e de outras rendas. A parte diretamente anti-inflacionária do programa Balcerowicz foi concebida de maneira a levar, por meio de redução das rendas reais e de algumas "âncoras", ao equilíbrio do mercado, tornando-o ao mesmo tempo o regulador principal dos processos econômicos. Trata-se aqui particularmente de radical redução de subsídios, imediata introdução da conversibilidade interna da moeda, associada à profunda desvalorização inicial, e também de notável redução de tarifas de importação; trata-se ainda da inflação - tanto corretiva quanto inercial - que reduziu novamente as poupanças; trata-se, ademais, da queda de aproximadamente $25 \%$ na produção industrial já no primeiro ano da implantação do Plano Balcerowicz, e de cerca de $12,5 \%$ do PIB, juntamente com o aparecimento de desemprego em massa, limitações aos aumentos de salários próximas de um congelamento que, em regime de elevada inflação, levaram à redução radical dos salários reais. Todos esses fatores exerceram influência decisiva quanto a uma nova estruturação da distribuição de renda.

Por que economistas e políticos atribuem tão pouca importância ao problema da distribuição de renda? Qualquer ensaio de resposta poderá ter apenas caráter tentativo. Aparentemente, nas mentes dos economistas três pontos de vista parecem estar firmemente codificados, resultando nesse desinteresse.

- Existe a convicção, bastante arraigada, de que o mercado atua de maneira justa no sentido de recompensar os fatores de produção (e de trabalho) de acordo com sua produtividade. A ingerência das autoridades apenas desvirtuaria essa atividade do mercado. Além disto, nas condições polonesas de déficit orçamentário e dívida pública bastante elevados, quaisquer ações por parte do Estado poderiam levar à diminuição dos meios de financiamento do crescimento econômico. Tal opinião parece prevalecer nos meios governamentais. Quando se percebe o problema, é apenas sub specie da pobreza e, mesmo assim, com a convicção de que estragar as coisas é fácil, difícil é consertá-las (9).

- Talvez ainda mais comum seja a suposição de que, durante a implantação das bases da economia capitalista, se torna imprescindível um período de acumulação primitiva de capital (por exemplo, o primeiro milhão deveria provir de especulação, roubo etc.). Este é um ponto de vista do século XIX. A evolução do processo de modernização capitalista de diversos países no século atual não confirma essa teoria. Não houve época de acumulação primitiva de capital nos países escandinavos ou na Áustria. Também o exemplo de modernização capitalista dos países asiáticos não indica a necessidade desse tipo de acumulação primitiva, que conhecemos da história da Inglaterra. A acumulação de excedente econômico naqueles países foi mais efeito da mobilização do Estado, graças à qual o processo de modernização foi acompanhado por redução radical da desigualdade. 
- A justificativa mais refinada de crescimento inicial da desigualdade é dada pela conhecida lei de Kuznets (1995). Ele demonstrou, com base em pesquisas empíricas, que as desigualdades de renda apresentam tendência de crescimento durante o período inicial da modernização capitalista, para só mais tarde decrescer (nos estágios mais avançados do desenvolvimento). Ultimamente, entretanto, tal lei vem sendo questionada. Pesquisadores britânicos são de opinião que Kuznets generalizou por demais rapidamente casos específicos, conhecidos principalmente na América do Sul (Atkinson \& Micklewright, 1992:37). Esquece-se que a Polônia e os outros países da Europa Central não necessitam de acumulação primitiva para tornar possível a passagem da manufatura para a fábrica.

Entre alguns políticos e economistas pode também surgir certo constrangimento em abordar claramente as questões que são socialmente mal recebidas. Referindo-se a situação análoga, Bent Furaker, um dos cientistas políticos suécos presentes à conferência de Torun, realizada em maio de 1992, observou que, em seu país, nenhum político conservador admitiria publicamente ser adversário da política de pleno emprego (realmente, políticos sociais poloneses, em sua visita à Suécia, espantaram-se ao perceber que o governo conservador de Bildt, ainda em 1992, publicava documentos planejando exatamente esse tipo de política).

\section{O que resulta das comparações internacionais?}

Apesar de as comparações internacionais de distribuição de renda encontrarem-se ainda em estado embrionário, pode-se esboçá-las até mesmo com a utilização do (tão imperfeito) Coeficiente de Gini. Na opinião de Milanovic (1995), a Eslováquia era, e continua sendo, o país mais igualitário, com o mesmo coeficiente de Gini (20) em 1987 e em 1993-94. O lugar seguinte é ocupado pela República Tcheca, com coeficientes de Gini de 19 e 27, respectivamente, nos dois períodos considerados (10). O governo da Tchecoslováquia, e depois da República Tcheca, já desde o seu segundo ano realizava a política de restauração no nível de salários vigente antes da terapia de choque. É verdade que no primeiro ano de realização do programa de estabilização (1991), os salários reais baixaram, na Tchecoslováquia, da mesma forma que na Polônia um ano antes, mas já nos dois anos subseqüentes tiveram crescimento de mais de 11\% (Adam, 1995: tab. 1). É interessante notar que na Hungria os processos de abertura de mercado, resultantes da reforma de 1968, não se expressaram em forma de desigualdades maiores que nos países do grupo de Visegrad. A Polônia era, nos últimos anos do socialismo real, o país menos igualitário: o coeficiente de Gini era 26 em 1987, quando a média para a Europa Central, incluídas a Bulgária e a Romênia, era 22. Mesmo após a terapia de choque ela manteve essa posição: o Gini em 1993-94, de acordo ainda com Milanovic, era 31 (11). Somente nos últimos anos ocorreu aumento da desigualdade (aumento do Coeficiente de Gini de 23, em 1989, para 28 em 1993-94), da mesma forma que na República Tcheca e na Eslovênia (Milanovic, 1995:14). O autor afirma que, na Polônia, o ritmo de crescimento da desigualdade foi semelhante ao da Grã-Bretanha nos tempos de M. Thatcher 
(13). A diferença consiste em que, neste país, o processo ocorreu em meio a desenvolvimento econômico moderado, enquanto na Polônia o crescimento da desigualdade ocorreu em época de drástica queda da renda nacional por habitante. Além disso, na Grã-Bretanha conseguiu-se ajustar a assistência social aos realmente necessitados, enquanto na Polônia tal assistência não alcançou resultado similar.

O reaquecimento econômico observado na Polônia, já no seu quinto ano, resultará em queda ou em aumento da desigualdade? Milanovic (1995:51) dá a sua opinião: "Depende do tipo de crescimento econômico; caso o crescimento da renda nacional se expresse apenas em crescimento das rendas altas e médias, as desigualdades aumentarão e a pobreza permanecerá no mesmo nível. É este o caso que temos, ao que parece, na Polônia - único pais pós-comunista cujo PIB cresceu por três anos consecutivo (1992-94) (TK). O PIB cresceu 10\% no período (as rendas reais individuais cresceram 7\%), enquanto a extensão da pobreza e o número de pobres permaneceram no mesmo nível - o que significa que as desigualdades cresceram. Todavia, se essa tendência se invertesse, a pobreza poderia se retrair rapidamente, já que as rendas da maior parte dos pobres estão apenas um pouco abaixo do nível da pobreza". Aprofunda-se outrossim a diferença entre o crescimento geral da riqueza e as rendas dos trabalhadores assalariados. Em 1992-1995, época do reaquecimento da economia, os salários reais aumentaram cerca de dez vezes menos que o Produto Interno Bruto.

As elites econômicas polonesas têm, portanto, um sério dilema pela frente. Se deixarem aos mecanismos de mercado a formação das rendas, então a Polônia juntar-se-á àqueles países, numerosos aliás, nos quais o PIB cresceu sensivelmente nos últimos quinze ou vinte anos, mas o número de pobres não diminuiu e suas rendas não aumentaram (13). Se optarem por uma política sócio-econômica consciente, cuja finalidade clara seria a redução das desigualdades, pelo menos até ao nível dos demais países da CEFTA - Área de Livre Comércio da Europa Central, e dos países da OECD - Organização para a Cooperação e o Desenvolvimento Econômico, cujas desigualdades conseguimos ultrapassar nos últimos anos (não só os países escandinavos, mas também a Alemanha, a Holanda e a Bélgica) (14), um país deverá enfrentar um desafio especialmente importante para a atual coalizão política, que chegou ao poder sob o lema da redução da desigualdade e dos fardos da transformação.

\section{Notas}

1 Os autores ilustram a sua tese com um gráfico de difícil reprodução (n.1, p.480). No eixo das coordenadas colocam, de um lado, a escala de aumento de PIB per capita e, do outro, o grau de desigualdade. Os dados referem-se a mais de trinta países pertencentes principalmente, pelo menos até há pouco tempo, ao grupo de países em desenvolvimento. Nos anos 1965-1989, todos os tigres asiáticos (Japão, Coréia do Sul, Indonésia, Hong Kong, Tailândia, Cingapura) caracterizavam-se por maior taxa de 
crescimento e menores amplitudes de renda. Naturalmente, um igualitarismo maior não garante de forma automática uma alta taxa de crescimento. Grande parte dos países é caracterizada por baixo grau de desigualdade, mas também por baixa taxa de crescimento. Entre esses encontram-se Grã-Bretanha, Bélgica, França, Austrália e, também, Argentina, Chile, Bolívia. O último grau - de maiores desigualdades e menores taxas de crescimento - é representado por Zâmbia, Peru, Quênia e México. O Brasil é caracterizado por maiores desigualdades e taxa de crescimento moderada (apesar de próximo à da Indonésia e Tailândia).

2 Os autores citam duas publicações descrevendo resultados de pesquisas empíricas (Spriggs et al, 1994; Card et al, 1995). Há pouco tempo, mais de uma centena de economistas dos EUA (Arrow, Klein e Tobin, entre outros) subscreveram um memorando pleiteando o aumento do salário mínimo. O pedido tinha por base dois fatos: o poder aquisitivo do salário mínimo é atualmente $26 \%$ menor que nos anos 70 ; verificou-se, a partir de vários estudos, que o aumento do salário mínimo no final dos anos 80 e começo dos 90 quase não afetou os níveis de emprego ou de preços (Staff Reporter, $1995)$.

3 Pouco se sabe sobre o assunto na Polônia. Segundo Milward (1996:29), historiador econômico da London School of Economics, "em 1949 a participação das edificações habitacionais, construídas pelo setor público, principalmente pelos governos locais com apoio financeiro nacional, era de mais de 70\% do total construído em França, Holanda, Alemanha, Noruega, Suécia e Grã-Bretanha. Na Holanda tal participação chegava a 97\%". O autor afirma também que em 1948 os salários reais dos trabalhadores na indústria da Europa Ocidental eram 20\% mais elevados que em 1938. Sublinha ainda que: "Em todos os países nos quais dados estatísticos são confiáveis, a participação dos salários na renda nacional cresceu de modo real, se comparada com a do período entre-guerras" (ibid: 18). Tal aspecto lança uma nova luz sobre a opinião corrente de que o período de reconstrução correspondeu a um aperto do cinto.

4 "Os aspectos distributivos da transformação econômica não se encontram no centro das atenções da opinião pública e das discussões acadêmicas acerca das mudanças na Europa Oriental (...). O aparecimento de novas desigualdades no período das transformações é tratada com desinteresse. Despertam mais atenção outros assuntos, como incentivos ao crescimento econômico, desequilíbrio macroeconômico, abertura de mercados, privatização de empresas estatais. São medidas de sucesso os indicadores agregados e o grau de aproximação aos mercados livres de comércio" (Atkinson $e t$ al, 1992:1).

5 Entre as raras publicações que analisam os efeitos distributivos da privatização encontra-se a de Chilosi (1995).

6 As regras que regulam a distribuição da renda nacional numa economia de mercado nascente deveriam ser diferentes (às vezes totalmente opostas) daquelas formadas pelo sistema do socialismo real. Além disso, a convicção bastante comum quanto ao sistema de socialismo real ter falhado, entre outras razões, por ser muito igualitário, expressou-se por uma reação anti-igualitária das novas elites políticas. Por regras entendemos aqui certas regularidades bem consolidadas (e sempre repetitivas), e não os princípios declarados nos programas, já que estes diferem muito dos reais, tanto num quanto noutro sistema político. Nos dois sistemas aparece o fenômeno da manipula- 
ção consciente da opinião pública, de afirmações que legalizam o sistema político. Por exemplo, estava distante da prática do socialismo real o tão propagado princípio de a cada qual segundo seu trabalho, assim como o princípio da igualdade, que assumia não apenas a igualdade das oportunidades, mas também certo igualitarismo de renda, ou seja, de limitação da disparidade de rendimentos. A realidade normalmente era diversa desses princípios, a ponto de se tornar uma bandeira de luta da oposição pela concordância de tais princípios com a prática. É semelhante à questão do princípio da igualdade de oportunidades proclamado pelo liberalismo, igualdade que seria realizada pelo mercado, recompensando os esforços de acordo com a produtividade. $\mathrm{Na}$ prática, entretanto, o mercado apresenta a tendência - como bem definiu Kuron (1994) - "de rebaixar os pobres e recompensar os ricos". Os princípios gerais podem ser anunciados de boa fé, refletindo as verdadeiras tendências de políticos, principalmente as dos "criadores" do novo sistema. Entretanto, no confronto com a realidade, tais princípios geram vários efeitos não-previstos e indesejáveis. As equipes responsáveis pelo acionamento dos processos que depois escapam ao seu controle, raramente o admitem abertamente, tendendo a justificar suas falhas através da "necessidade histórica" ou por circunstâncias independentes dos seus propósitos.

7 A expressão é de Mieczyslaw Kabaj. Em seu estudo sobre as transformações sistêmicas na Polônia, Heyns (1995) apresentou, sob forma de diagrama, o grau de dependência das famílias com relação ao Estado nos anos 1992-93. Trata-se de unidades econômicas, que recebem mais da metade das suas rendas de empresas estatais ou do próprio Estado - rendas do trabalho no setor público, pensões, aposentadorias, auxílios a desempregados ou, mesmo, subsídios oferecidos pela assistência social. No total, cerca de $75 \%$ das famílias são dependentes do Estado do ponto de vista de seus rendimentos, e o processo de sua desestatização processa-se muito lentamente. A autora conclui: "A redução do número de empregos no setor estatal não leva à sensível redução - pelo menos ainda - dos custos de manutenção do setor público numa concepção mais ampla da palavra... Enquanto a dinâmica do setor privado não resultar na diminuição do grau de dependência da sociedade ao Estado, o sistema (social TK) permanecerá, na realidade, inalterado" (ibid: 137).

$8 \mathrm{O}$ mais conhecido e talvez o mais abrangente atestado de mudança de opinião foi dado por Kuron. Em 1989 ele promoveu Jeffrey Sachs a conselheiro do governo, apoiou fortemente o programa de Balcerowicz e até "suspendeu" publicamente suas idéias esquerdistas. Kuron era de opinião que somente após a criação de bases para economia do mercado haveria lugar e tempo para sua "democratização social". Alguns anos mais tarde, chegou á conclusão que o desemprego em massa e de longa duração, assim como a pobreza de grande parte da sociedade constituíam ameaças a reformas subseqüentes (Kuron, 1994). Foi exatamente em nome de um desenvolvimento sadio da economia de mercado que ele questionou tanto o seu ritmo, quanto a sua profundidade. Estava convencido de que o ocorrido em termos de mudança nas condições materiais de vida, na Polônia, tornou-se importante freio para reformas futuras.

9 A Agência Central de Planejamento constatou que a progressiva diferenciação das rendas gerou frustração social e protestos. Por isso colocou aos ministros e às administrações centrais a seguinte pergunta: "O governo deve levar adiante a política de diferenciação orientada nos níveis de renda da população (...) ou deixar a questão da 
estrutura da renda para o jogo do mercado?" (Centralny, 1995a:10). Em minha opinião, mesmo a justificativa desta pergunta é altamente perturbadora. Cito-a por extenso: "A ampliação da ingerência na formação dos níveis de renda pode facilmente se transformar em uma política igualitária e exigir um aumento na escala da redistribuição; o que levaria a uma sensível sobrecarga no orçamento do país, com o financiamento das baixas rendas. Como conseqüência, criar-se-ia sensível restrição à capacidade do orçamento de financiar o crescimento econômico, e constituir-se-ia barreira real ao progresso. Como efeito desses fatores, poderiam ser fortalecidas atitudes reivindicatórias por parte dos diversos grupos sócio-profissionais, aumentando a pressão sobre as estruturas do Estado como garantidor da melhoria da situação material da população. Tal pressão resultaria em aumento dos encargos orçamentários (remunerações pagas pelo Estado, benefícios sociais). Por outro lado, a progressiva diversificação das rendas (resultante dos processos de mercado) poderia levar a aprofundamento e consolidação das regiões de pobreza, o que resultaria em altos custos sociais" (p. 10-11). Ao comparar posições e propostas especificas apresentadas aos "Dilemas da evolução sócio-econômica" (Centralny, 1995a) percebe-se que a Agência anotou somente (!) duas declarações merecedoras de atenção (talvez não tivesse recebido outras), as quais são citadas por extenso.

Academia Polonesa de Ciências (PAN): "A pergunta foi formulada de maneira imprópria. O governo sempre exerce política de correção da estrutura de rendas determinada pelo mercado (as soluções podem aí ser mais ou menos igualitárias). Contrariando opiniões correntes, pesquisas não confirmam a tese do aumento da esfera de pobreza na Polônia”.

Voivoda (governador) de Bielsk: "Proponho deixar a questão da formação da estrutura de rendas para o jogo do mercado, aumentando as possibilidades de financiamento do crescimento através do orçamento".

10 Foram utilizados, para as comparações, os cálculos de Branko Milanovic. De acordo com cálculos de Beskid (1995:tabelas l e 2), baseados em resultados da pesquisa sobre Condições de vida, necessidades e aspirações da sociedade polonesa em 1989, assim como em Sondagens sociais gerais polonesas, o Coeficiente de Gini foi, tanto em 1989 quanto em 1993 e 1994, bem mais elevado: respectivamente, 29, 37 e 36.

11 Não disponho do Coeficiente de Gini referente à Hungria para os anos anteriores a 1989. Entretanto, em uma tabela de distribuição da renda per capita por decís estudada por Andorka (1994), observa-se que a proporção do décimo decíl com relação ao primeiro cresceu um pouco nos primeiros anos após a reforma de 1968, decaindo depois sensivelmente, para novamente crescer na segunda metade dos anos 80 . Eis os anos e as relações entre o $10^{\circ}$ e o $1^{\circ}$ decis: $1962-5,2 ; 1967-4,7 ; 1972-4,9 ; 1977-3,8$; $1982-3,8 ; 1987-4,6$. Nos últimos anos tal relação cresceu significativamente: 1992 6,$55 ; 1994-7,05$ (Andorka, 1995: tabelas 2 e 3).

12 Entre os anos 1979 e 1990 a participação do quintil mais alto nas rendas pessoais cresceu de $36 \%$ para $43 \%$ e a participação do quintil mais baixo caiu de $10 \%$ para $6 \%$, conforme Townsend (1995), com base em dados do Central Statistical Office (1995).

13 Ferge (1995:4) informa, com base em dados de pesquisadores britânicos, que nos anos 1980-1991 as desigualdades aumentaram em 11 dos 18 países mais ricos. 
14 O perito da Academia Polonesa de Ciências (nota 9) tem evidentemente razão ao afirmar que o Estado sempre efetua correções na distribuição da renda nacional. Tais correções podem ser imperceptíveis, favorecer o aumento da desigualdade, ou serem inconseqüentes - dependendo principalmente do ciclo das campanhas eleitorais. Levando-se, entretanto, em consideração o caráter das mudanças que têm ocorrido e estão ocorrendo na Polônia, o dilema formulado pela Agência Central de Planejamento continua sendo legítimo. Tal fato é perfeitamente demonstrado pela opinião do governador de Bielsk (nota 9), quando afirma que a distribuição de renda ocorrida espontaneamente atende melhor ao crescimento econômico.

Referências bibliográficas

ADAM, Jan. The transition to a market economy in Hungary. Europe-Asia Studies, v. 47, n. $6,1995$.

ANDORKA, Rudolf. The development of poverty during the transformation in Hungary. Texto apresentado no seminário sobre LONG-TERM STRUCTURAL CHANGES IN EAST AND CENTRAL EUROPE, organized by Sudosteuropa Gesellschaft, München, junto com o Center for European and Russian Studies, UCLA, WeimarJena, 27-30 abril, 1995.

ATKINSON, Anthony B. \& MICKLEWRIGHT, John. Economic transformation in Eastern Europe and the distribution of income. Cambridge, 1992.

BAILY, Martin Neil; BURTLESS, Gary \& LITAN, Robert E. Growth with equity: economic policymaking for the next century. Washington D.C., Brooking Institutions, 1993.

BESKID, Lidia. Percepcja spoleczna sytuacji materialnej i jej zróznicowan w latach 19901994. Trabalho realizado com apoio do Instituto de Economia da Academia Polonesa de Ciências, 1995.

BESKID, Lidia \& DENISZCZUK, Lucyna. Sytuacja materialna ludnosci $i$ jej zróznicowanie (1989-1994). Trabalho realizado com apoio do Instituto de Economia da Academia Polonesa de Ciências, 1995.

BIRDSDALL, Nancy; ROSS, David \& RICHARD, Sabot. Inequality and growth reconsidered: lessons from East Asia. The World Bank Economic Review, v. 9, n. 3, 1995.

BURTON, John. The instability of the middle way. In: Norman Barry et al, Hayek's "Selfdom" revisited, London, 1984.

BYWALEC, Czeslaw. Poziom zycia spoleczenstwa polskiego na tle procesów transformacji gospodarczej (1989-1993). Estudo preparado por solicitação do Instituto de Economia da Academia Polonesa de Ciência, 1995.

CARD, David \& KRUEGER, Alan B. Myth and measurement: the new economics of the minimum wage. Princeton, 1995.

CENTRAL Statistical Office. Social Trends, London, 1995. 
CENTRALNY Urzad Planowania. Dylematy rozwoju spoleczno-gospodarczego. Varsóvia, ago. 1995a [mimeo].

Zestawienie stanowisk $i$ propozycji szczegolowych zgloszonych do

'Dylematow rozwoju spoleczno-gospodarczego'. Varsóvia, ago. 1995b [mimeo].

CHILOSI, Alberto. Distributional and social consequences of privatization in the economies in transition: an analytical framework. Texto apresentado ao VWORLD CONGRESS OF CENTRAL AND EAST EUROPIAN STUDIES, Varsóvia, ago. 1995.

DEPARTMENT Rozwoju Spolecznego Centralnego Urzedu Planowania. Zmiany w sferze spolecznej w latach 1989-1994. Gospodarkà Narodowa, n. 12, dez. 1995.

EATWELL, John et al. Transformation and integration. Shaping the future of Central and Eastern Europe. London, 1995.

FERGE, Zsuzsa. Is the world falling apart? A view from the East. Texto apresentado à CONFERENCE ON LONG-TERM STRUCTURAL CHANGES IN EAST AND CENTRAL EUROPE, organized by Sudosteuropa Gesellschaft, Müchen, em conjunto com o Center for European and Russian Studies. UCLA, Weimar-Jena, 27-30 de abril 1995.

FREEMAN, John R. Democracy and markets. The politics of mixed economies. IthacaLondon, 1991.

HAYEK, Friederich A. von. Social or distributive justice (1976). In: Nishiyama, C \& Lube, K.R. (ed.) The essence of Hayek. Stanford, 1984.

. The principles of a liberal social order (1967). In: The essence of Hayek. cit.

HEYNS, Barbara. The dynamics of market transition. Final report to the National Council on Soviet and East European Research. New York, jul. 1995.

KURON, Jacek. Rzeczpospolita dla kazdego. Zycie Gospodarcze, n. 21, 1994.

KUZNETS, Simon. Economic growth and income inequality. American Economic Review, v. 45, n. $2,1995$.

MILANOVIC, Branko. Poverty, inequality and social policy in transition economies. Washington D.C., The World Bank, 1995a.

A cost of transition: 50 million poor and growing inequality, The World Bank, Transition. The Newsletter about reforming economies, v.5, n. 8, out. 1995 b.

MILWARD, Alan. The life and death of the Great European Boom. Texto apresentado ao ANNUAL COLLOQUIUM SERIES: THE MEANING OF THE MARKET II. Los Angeles, UCLA, 12 fev. 1996.

MISHEL, Lawrance; BERNSTEIN, Jared \& RUSELL, Edith. Who wins with a higher minimum wage. Washington D.C., The Economic Policy Institute, 1995.

OKUN, Artur M. Equality and efficiency: the big trade-off. Washington D.C., Brookings Institution, 1975. 
OKUN, Artur M. Further thought on equality and efficiency. Washington D.C., Brookings Institution, 1976.

1983.

Economics for policymaking, Washington D.C., Brooking Institution,

SACHS, J. Poland's jump in the market economy. Cambridge Mass., London, 1993.

SIMPSON, David. Schumpeter and capitalism in the era of transition. In: David Reisman (ed.). Economic thought and political theory. Boston/London, Dordrecht, 1994.

SPRIGGS, William \& KLEIN, Bruce. Raising floor: the effects of the minimum wage on low-wage workers. Washington D.C., 1994.

STAFF Reporter. Economists back proposal to lift minimum wage. Wall Street Journal, 3 out. 1995.

TOWNSEND, Peter. Persuasion and conformity: an assesment of the Borrie Report on Social Justice. The New Left Review, n. 213, 1995.

UNDP -United Nations Development Program. Polska '95. Raport o rozwoju spolecznym. Warszawa, 1995.

Tadeusz Kowaliké professor de Economia e Humanidades no Instituto de Economia da Academia Polonesa de Ciências. Foi pesquisador no Wilson Center, em Washington e no Center for European Russian Studies, da UCLA, Califórnia, tendo lecionado também na New School for Social Research, de NewYork.

$\mathrm{O}$ autor elaborou o texto apoiado quase que exclusivamente (quanto à fonte de informação) em três estudos encomendados pelo Instituto de Economia da Academia Polonesa de Ciências (Beskid, 1995; Beskid \& Deniszczuk, 1995; Bywalec, 1995).

Tradução de Adam Polakiewicz. Revisão de Witold Zmitrowicz e Lenina Pomeranz. O original em polonês - Zmiany w Podziale Dochodu Narodowego w Czasie Transformacjiencontra-se à disposição do leitor no IEA-USP para eventual consulta.

Estudos AvanÇAdOS 10 (28), 1996 